\title{
Modelling the exceptional Baltic Sea inflow events in 2002-2003
}

\author{
Andreas Lehmann, ${ }^{1}$ Philip Lorenz, ${ }^{2}$ and Daniela $\mathrm{Jacob}^{2}$ \\ Received 24 June 2004; accepted 19 October 2004; published 13 November 2004.
}

[1] During 2002 and 2003 exceptional inflow events have been registered. In January 2003 a massive inflow of highly saline, cold and extremely oxygen-rich water from the North Sea was recorded at Darss Sill. This event is considered to be the most important inflow since 1993. A coupled model system for the Baltic Sea region, called BALTIMOS, was developed in the frame of DEKLIM/ BALTEX by linking existing model components for the atmosphere (model REMO), for the ocean including sea ice (model BSIOM), for the hydrology (model LARSIM) as well as for lakes. The model system consists of high resolution model components: $1 / 6^{\circ}(\sim 18 \mathrm{~km})$ with 20 vertical levels; ocean-ice $5 \mathrm{~km}$ with 60 vertical levels, hydrology $1 / 6^{\circ}$. The model domain covers the whole drainage basin of the Baltic Sea as well as major parts of Europe. The exceptional inflow events have been simulated successfully with BALTIMOS. The simulation was initialized at 1st of February 2002 and the model has been run until October 2003. This period includes the exceptional warm water inflow in autumn 2002 and the major Baltic inflow in January 2003. Different inflow characteristics are presented and discussed. The simulated volume transport for the major inflow in January 2003 amounts to about $250 \mathrm{~km}^{3}$, half of which was of salinity 17 PSU which corresponds to a salt transport of $2.7 \times 10^{12} \mathrm{~kg}$. INDEX TERMS: 4243 Oceanography: General: Marginal and semienclosed seas; 4255 Oceanography: General: Numerical modeling; 4215 Oceanography: General: Climate and interannual variability (3309); 4247 Oceanography: General: Marine meteorology; 4512 Oceanography: Physical: Currents. Citation: Lehmann, A., P. Lorenz, and D. Jacob (2004), Modelling the exceptional Baltic Sea inflow events in 2002-2003, Geophys. Res. Lett., 31, L21308, doi:10.1029/2004GL020830.

\section{Introduction}

[2] Effective saltwater intrusions into the Baltic Sea (Figure 1) are governed by special atmospheric conditions over the western Baltic Sea [Schinke and Matthäus, 1998] causing out of phase variations of sea levels in the Kattegat and the western Baltic Sea. The resulting barotropic flow will alter direction as the sea level of the Kattegat varies with air pressure and wind set up. Stronger-than-average westerlies are the necessary pre-condition for a massive salt water intrusion to occur, but also a number of other factors play an important role [Schinke and Matthäus, 1998; Matthäus and Schinke, 1994; Meier and Döscher, 2003]. Further discussed as controlling mechanisms are the

\footnotetext{
${ }^{1}$ Leibniz Institute for Marine Sciences, Kiel, Germany.

${ }^{2}$ Max-Planck-Institute for Meteorology, Hamburg, Germany.
}

frequency and path of low pressure systems, the mean sea level (storage) of the Baltic Sea and the stratification in the Danish Sounds including the position of the Belt Sea front which in turn is determined by precursory in- and outflow conditions [Lehmann and Hinrichsen, 2000].

[3] Highly saline water which has penetrated into the Arkona Basin often forms a dense bottom pool. Further flow as dense bottom current into the Bornholm and Gotland Basin can take several months, where an effective exchange between the sub-basins of the Baltic Sea is again controlled by prevailing atmospheric conditions.

[4] In January 2003 an exceptional inflow of highly saline and oxygenated water into the Baltic Sea was registered. This inflow was able to effectively change the oxygen and saline conditions in the deep basins of the Baltic Sea. It is considered to be the most important inflow since 1993.

[5] Between January 16th and 25th inflow of highly saline, cold and extremely oxygen-rich water from the North Sea was recorded at Darss Sill. Calculations using the sea level difference of about $50 \mathrm{~cm}$ at the Landsort gauge yielded an estimate of $200 \mathrm{~km}^{3}$ (for comparison the annual river runoff is about $450 \mathrm{~km}^{3}$ ). Such exceptional inflows are the only possibility to renew the deep water of the central Baltic Sea and improve the oxygen situation there. The reason for this exceptional inflow was an unusual low water level $(20-30 \mathrm{~cm}$ below normal at gauge Stockholm) at the beginning of the inflow due to stable high pressure over Scandinavia and associated north-easterly winds. From January 11th the wind turned to westerly directions and the wind speeds increased reaching about $20 \mathrm{~m} / \mathrm{s}$ during January 15th (Figure 2). The western Baltic Sea level suddenly lowered to $-80 \mathrm{~cm}$ and a strong inflow was forced. The intrusion continued with heavy fluctuations until the wind began fading on January 18th, the Stockholm level rose to $25 \mathrm{~cm}$ above normal. A detailed description of the temporal and spatial evolution of the Baltic inflow is given by Feistel et al. [2003a] and Piechura and Beszczynska-Möller [2003].

\section{Coupled Regional Climate Model System BALTIMOS}

[6] In the frame of the BALTic sea EXperiment (BALTEX) a fully coupled model system for the Baltic Sea region, called BALTIMOS (http://www.baltimos.de), was developed by linking existing model components for the atmosphere (REMO) [Jacob, 2001], the ocean including sea ice (BSIOM) [Lehmann and Hinrichsen, 2000, 2002] and for hydrology (LARSIM) [Bremicker, 2000] as well as for lakes and vegetation. This investigation was funded by DEKLIM (German Climate Research Programme 2001-2006; http:// www.deklim.de). The model system consists of high resolution model components: atmosphere $1 / 6^{\circ}(\sim 18 \mathrm{~km})$ with 


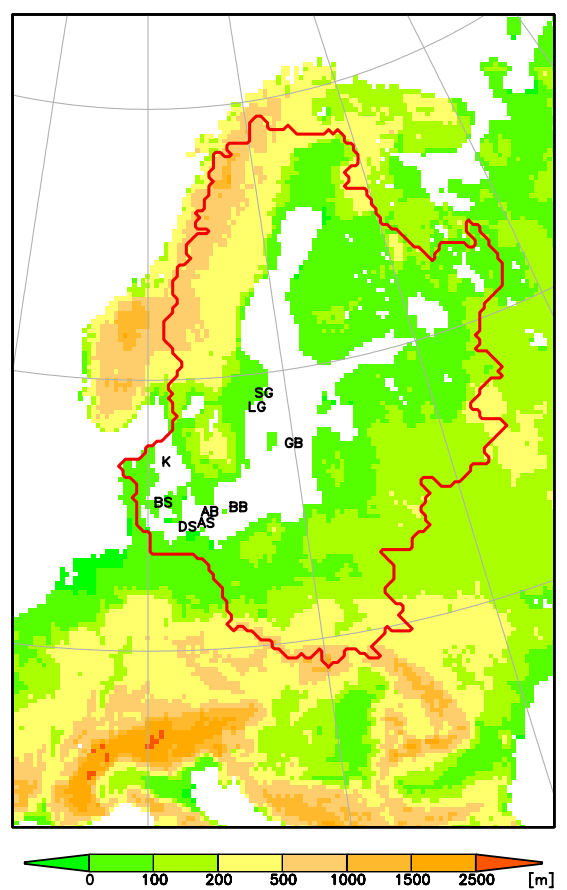

Figure 1. Orography $[\mathrm{m}]$ of the BALTIMOS model domain with BALTEX catchment area (red line). $\mathrm{K}=$ Kattegat, BS $=$ Belt Sea, DS $=$ Darss Sill, AS $=$ Arkona Station, $\mathrm{AB}=$ Arkona Basin, $\mathrm{BB}=$ Bornholm Basin, $\mathrm{GB}=$ Gotland Basin, $\mathrm{LG}=$ Landsort Gauge, $\mathrm{SG}=$ Stockholm Gauge.

20 vertical levels; ocean-ice $5 \mathrm{~km}$ with 60 vertical levels, hydrology $1 / 6^{\circ}$, which are coupled via surface fluxes. The model domain covers the whole drainage basin of the Baltic Sea as well as major parts of Europe (Figure 1). BALTIMOS is run in the so-called climate mode where the model domain is initialized only once at the beginning of the simulation, and during the integration only lateral boundary fields are updated. In a zone of 8 grid rows from the boundary towards the inner model domain a relaxation scheme according to Davies [1976] has been applied. As a consequence of the reduced influence of the forcing fields, the model has the possibility of a more or less independent development in the inner part of the model domain. Initial fields for the ice-ocean component have been provided from uncoupled model runs which have been forced by observed atmospheric forcing fields provided by the SMHI (Swedish Meteorological and Hydrological Institute Norrköping, Sweden).

[7] The development of the model system is a combined effort of 10 different German institutions with the focus on model validation rather than long-term climate simulations (which will be performed later). Thus, the simulated water and energy budget of the Baltic Sea area undergoes a comprehensive validation which is carried out by the project partners.

\section{Simulation of Exceptional Inflow Events in 2002 and 2003}

[8] The simulation with the coupled atmospheric and oceanographic components of BALTIMOS using climato- logical values for river runoff was initialized at 1 st of February 2002 and continuously integrated until the end of October 2003. As initial and boundary conditions for the atmospheric component re-analysis provided by the European Centre for Medium-Range Weather Forecasts (ECMWF) have been used (due to the lack of further reanalysis the integration had to be stopped at end of October 2003). Figure 2 shows wind speed and direction of the SYNOP station "Arkona" (island of Rügen) compared to BALTIMOS results of the appropriate grid box for January-April 2003. Despite the principal difficulty of comparing a point measurement (station) with a representative value for the area of a whole grid box (model result), there is a good agreement between them for January. In particular the shift from easterly winds in the beginning of January to strong westerly winds in the middle of January is represented very well. However, the agreement for February 2003 is low, but getting again better for March and April. The model simulation was performed in "climate mode" (see chapter 2) leading under certain atmospheric conditions to considerable temporal deviations of the simulated wind patterns from the observations [Hagedorn et al., 2000]. In general, the comparison demonstrates that the simulated wind fields are in close agreement with observations. Because massive Baltic Sea inflow events are initiated by a specific sequence of wind conditions, this is an essential precondition for a realistic simulation of inflow events with a coupled model system.

[9] The realistic simulation of in- and outflow events is demonstrated by a comparison of simulated and observed sea level elevations at Landsort gauge (Figure 3). Landsort gauge is a representative of the mean sea level of the Baltic Sea thus, representing the mass exchange with the Kattegat. During the simulation period several strong in- and outflow events occur. However, only those events which affect the temperature and salinity structure in the Bornholm Basin will be discussed here. Generally, the overall agreement

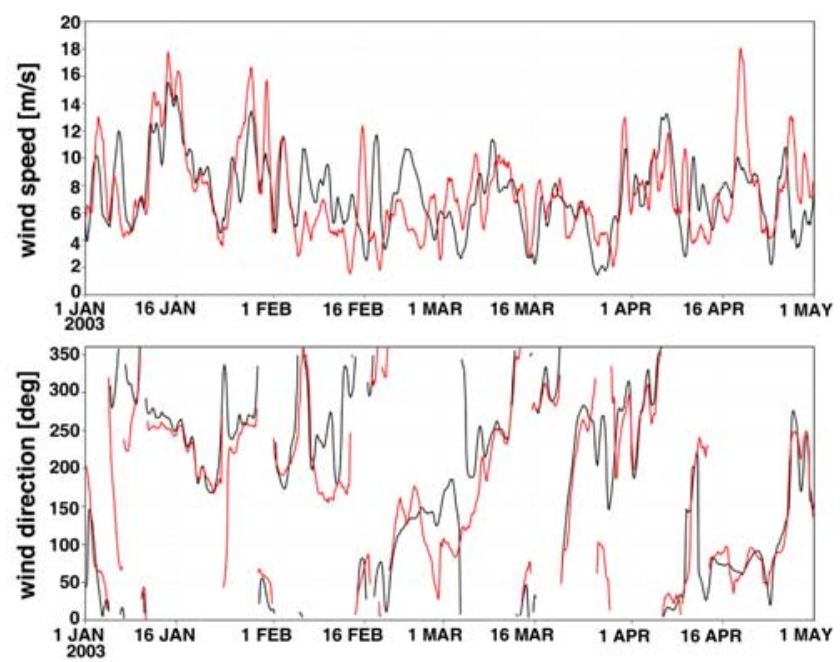

Figure 2. Running daily means of wind speed $[\mathrm{m} / \mathrm{s}]$ (upper panel) and wind direction [deg] (lower panel) for January-April 2003: Measurements at the SYNOP-Station "Arkona" (red) and BALTIMOS simulation for the appropriate grid box (black). 


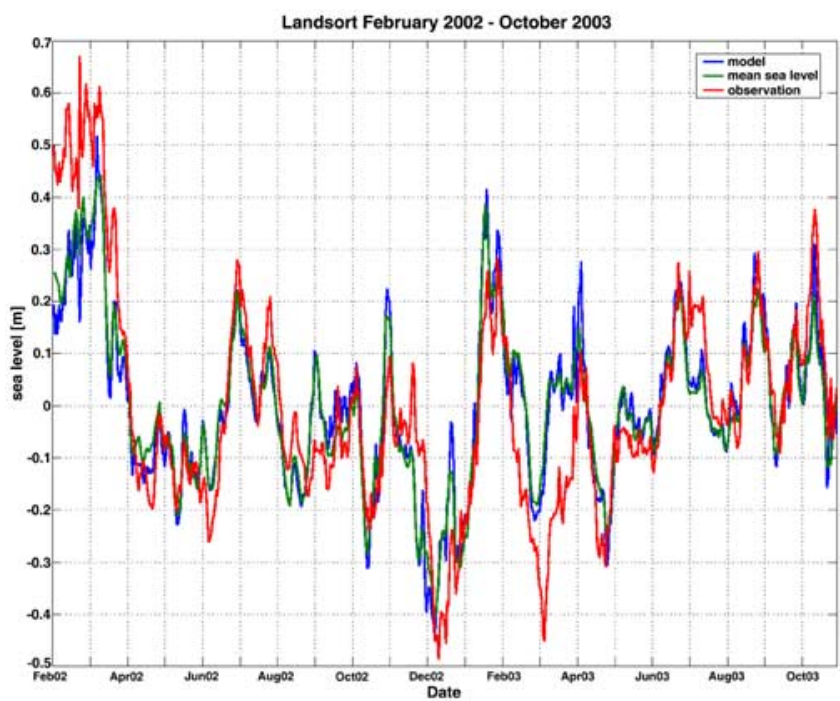

Figure 3. Sea level at Landsort gauge from February 2002 to October 2003. Red line: observations, blue line: model and green line: simulated mean sea level of the Baltic Sea.

between simulation and observation is high. Deviations occur primarily due to the climate mode (compare with Figure 2).

[10] In accordance to observations [Feistel et al., 2003b], unusual warm water entered the Bornholm Basin in September 2002 leading to temperatures of $14-15^{\circ} \mathrm{C}$ in depths between 60 and $70 \mathrm{~m}$ in the beginning of October (Figure 4). This persistent warm water anomaly in the Bornholm Basin was finally displaced by the inflow in January 2003 [Feistel et al., 2003a]. Due to the very warm summer in 2003, a further inflow of moderate salinity caused again a temperature increase in September 2003. Both warm water inflows were accompanied by a slight increase in salinity in depths between 60 and $80 \mathrm{~m}$. Due to the inflow in January 2003 and fast movement of the intruded highly saline water through the Arkona Basin, a rapid increase in
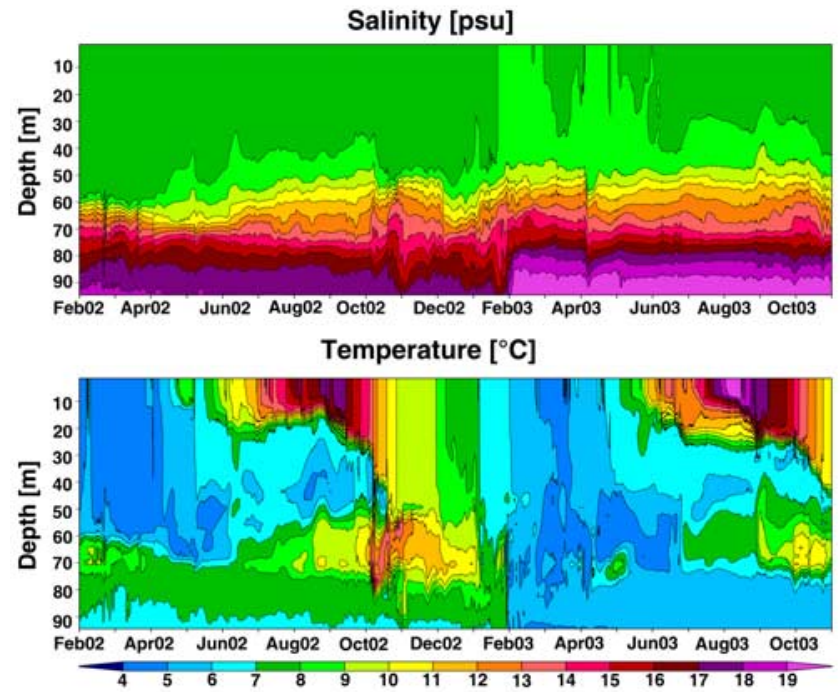

Figure 4. Time series of vertical profiles of salinity [PSU] (upper panel) and temperature $\left[{ }^{\circ} \mathrm{C}\right]$ at Bornholm Deep vs. time from February 2002 until October 2003. salinity ( $>19$ PSU) occurred at the beginning of February. High salinity near the bottom of the Bornholm Deep was persistent until the end of the simulation period.

[11] The exceptional warm water inflow occurred between August and October 2002. Due to the absence of strong barotropic pressure gradients (mainly sea level differences between southern Kattegat and western Baltic Sea) during this period, the often less important baroclinic pressure gradients (mainly horizontal salinity differences) controlled the inflow of higher saline and warm water into the Baltic Sea. Feistel et al. [2003b] gave estimates for the inflow: $190 \mathrm{~km}^{3}$ outflow and a simultaneous $90 \mathrm{~km}^{3}$ inflow of 16 PSU, yielding a salt transport of $1.4 \times 10^{12} \mathrm{~kg}$ by the latter. These very rough estimates can not fully be supported by our model results. Firstly, there was no continuous outflow anomaly during August to October 2002 (Figure 3). The extended outflow period started in July, and was interrupted by an inflow in the end of August and in mid-September. The outflow period ended in the beginning of October 2002. From the model the total inflow can be directly measured by the flow through the Danish Sounds (Figure 5). Additional to the mean outflow of $45 \mathrm{~km}^{3}$ per month, $60 \mathrm{~km}^{3}$ of water left the Baltic Sea. In total an outflow of $165 \mathrm{~km}^{3}$ was simulated for the period $1 \mathrm{st}$ August to 10th October 2002. Simultaneously, there was an inflow of $52 \mathrm{~km}^{3}$ of water with salinity $>12$ PSU, yielding a salt transport of $0.9 \times 10^{12} \mathrm{~kg}$.

[12] For the major inflow in January 2003, the observed inflow characteristics are based on much more observations. Thus, the agreement between modeled and observed (estimated) transports is much higher. From sea level measurements at Landsort (Figure 3) a sea level rise of about $0.62 \mathrm{~m}$ can be deduced (taking the difference from the end of December to the mid of January). This corresponds to a total volume change of $234 \mathrm{~km}^{3}$. The total simulated sea level rise is $0.68 \mathrm{~m}$ which corresponds to $257 \mathrm{~km}^{3}$. The flow through the Danish Sounds amounts to $240 \mathrm{~km}^{3}$, with

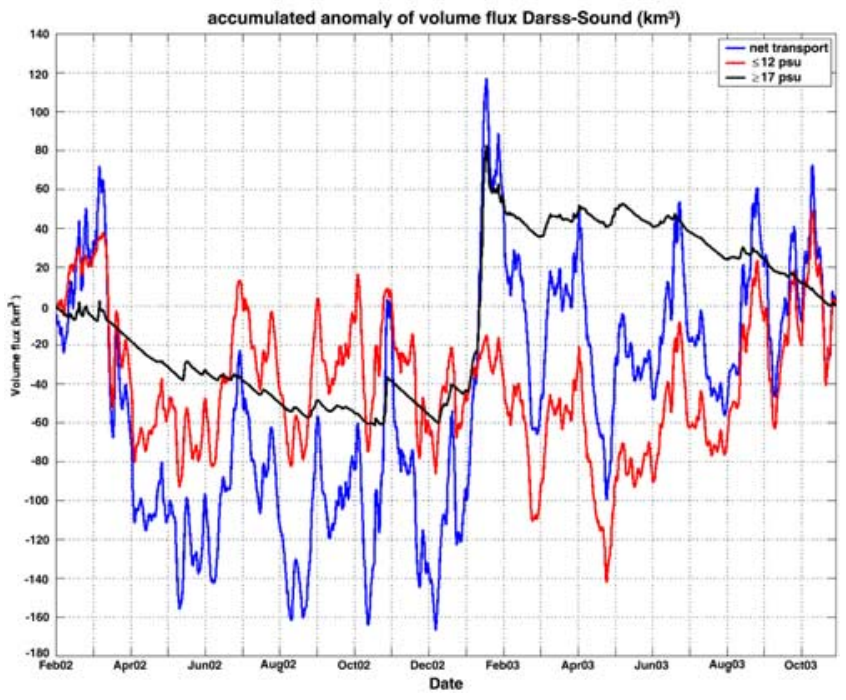

Figure 5. Accumulated anomaly of volume flux through the Danish Sounds from February 2002 to October 2003 (blue line: net transport, red line: volume flux $\leq 12$ PSU and black line: volume flux $\geq 17$ PSU. Generally, an increase in volume flux means inflow, a decrease outflow. 
$127 \mathrm{~km}^{3}$ of water with a salinity $>17$ PSU. Even the total amount of salt which entered the Baltic Sea during the inflow event can be directly calculated from the simulation. During the inflow in January 2003 a total of $4 \times 10^{12} \mathrm{~kg}$ of salt entered the Baltic Sea with $2.7 \times 10^{12} \mathrm{~kg}$ of water with salinity $>17$ PSU. For the simulation period, the mean volume flux out of the Baltic Sea $\left(\mathrm{Q}_{\mathrm{o}}\right)$ was calculated to be $25,595 \mathrm{~m}^{3} / \mathrm{s}$ and the flow into the Baltic Sea $\left(\mathrm{Q}_{\mathrm{i}}\right)$ was $12,324 \mathrm{~m}^{3} / \mathrm{s}$ with a residuum $(\mathrm{R})$ of $13,271 \mathrm{~m}^{3} / \mathrm{s}$. These values are considerable smaller than the mean values $\left(\mathrm{Q}_{\mathrm{o}}=\right.$ $33,000 \mathrm{~m}^{3} / \mathrm{s}, \mathrm{Q}_{\mathrm{i}}=18,000 \mathrm{~m}^{3} / \mathrm{s}, \mathrm{R}=15,000 \mathrm{~m}^{3} / \mathrm{s}$ ) which have been determined form a 25 -year uncoupled simulation. Feistel et al. [2003a] gave estimates for the extraordinary inflow event in January 2003. The total inflow volume was estimated to $200 \mathrm{~km}^{3}$ with half of which $\left(97 \mathrm{~km}^{3}\right)$ of salinity $>17$ PSU, yielding an import of $2 \times 10^{12} \mathrm{~kg}$. Thus, the agreement between the simulated transports and estimations based on observations is high indicating the applicability of BALTIMOS for budget calculations.

\section{Conclusions}

[13] It is the first time that a fully coupled regional model (BALTIMOS) has been successfully applied to simulate extraordinary inflow events into the Baltic Sea and to validate the results by observational evidence.

[14] The period from February 2002 to October 2003 includes the exceptional inflow in January 2003 and also some smaller inflows in 2002 and 2003 which significantly change the salinity and temperature distribution in the deep basins of the Baltic Sea. Model results are in close agreement with observations [Feistel et al., 2003a, 2003b]. We could demonstrate that not only the overall mass exchange (sea level changes at Landsort) was satisfactorily described by the model, also the further flow of water entering the Baltic Sea during different inflow events and its distribution in the Bornholm Basin could be successfully reproduced. Estimates of inflow characteristics [Feistel et al., 2003a, $2003 \mathrm{~b}$ ] could be verified by our model results.

[15] The results of the coupled model BALTIMOS demonstrates the powerful applicability of coupled numerical simulations. The strategy behind BALTIMOS is to develop a model system which can be utilized for present day simulations of the Baltic area with the focus to understand present day climate variability, and also run the model for climate change scenarios.

[16] Acknowledgment. This research was funded by the German Climate Research Programme (DEKLIM) of the Federal Ministry of Education and Research (BMBF) within the projects BALTIMOS (contract no. 01 LD 0027) and BASEWECS (contract no. 01 LD 0025).

\section{References}

Bremicker, M. (2000), Das Wasserhaushaltsmodell LARSIM-Modellgrundlagen und Anwendungsbeispiele, Freiburger Schr. Hydrol., vol. 11, Inst. für Hydrol. der. Univ. Freiburg, Freiburg, Germany.

Davies, H. C. (1976), A lateral boundary formulation for multi-level prediction models, Q. J. R. Meteorol. Soc., 102, 405-418.

Feistel, R., G. Nausch, W. Matthäus, and E. Hagen (2003a), Temporal and spatial evolution of Baltic deep water renewal in spring 2003, Oceanologia, 45, 623-642.

Feistel, R., G. Nausch, V. Mohrholz, E. Lysiak-Pastuszak, T. Seifert, W. Matthäus, S. Krüger, and I. S. Hansen (2003b), Warm waters of summer 2002 in the deep Baltic Proper, Oceanologia, 45, 571-592.

Hagedorn, R., A. Lehmann, and D. Jacob (2000), A coupled high resolution atmosphere-ocean model for the BALTEX region, Meteorol. Z., 9, 7-20.

Jacob, D. (2001), A note to the simulation of the annual and inter-annual variability of the water budget over the Baltic Sea drainage basin, Meteorol. Atmos. Phys., 77, 61-73.

Lehmann, A., and H.-H. Hinrichsen (2000), On the thermohaline variability of the Baltic Sea, J. Mar. Syst., 25, 333-357.

Lehmann, A., and H.-H. Hinrichsen (2002), Water, heat and salt exchange between the deep basins of the Baltic Sea, Boreal Environ. Res., 7, 405415.

Matthäus, W., and H. Schinke (1994), Mean atmospheric circulation patterns associated with Major Baltic Inflows, Dtsch. Hydrogr. Z., 46, $321-338$.

Meier, H. E. M., and R. Döscher (2003), A multiprocessor coupled iceocean model for the Baltic Sea: Application to salt inflow, J. Geophys. Res., 108(C8), 3273, doi:10.1029/2000JC000521.

Piechura, J., and A. Beszczynska-Möller (2003), Inflow waters in the deep regions of the southern Baltic Sea-Transport and transformation, Oceanologia, 45, 593-621.

Schinke, H., and W. Matthäus (1998), On the causes of major Baltic inflows an analysis of long time series, Cont. Shelf Res., 18, 67-97.

D. Jacob and P. Lorenz, Max-Planck-Institute for Meteorology, Bundesstr. 50, D-20146 Hamburg, Germany.

A. Lehmann, Leibniz Institute for Marine Sciences, Düsternbrooker Weg 20, D-24105 Kiel, Germany. (alehmann@ifm-geomar.de) 